Middle East Journal of Science(MEJS)

\title{
EVALUATING OF UPHILL TIMBER SKIDDING WITH FORESTRY TRACTOR
}

\section{Neşe Gülci ${ }^{l}$ Sercan Gülci ${ }^{1}$, Kıvanç Yüksel}

${ }^{1}$ Kahramanmaraş Sütçü İmam Üniversitesi, Orman Fakültesi, 46100, Kahramanmaraş, Türkiye

*sgulci@ksu.edu.tr

In our country, timber haulage operations in forestry are mostly carried out with human power, animal power and tractors. The use of tractors are inevitable as it becomes impossible to uphill transport with human and animal power when the logs place under the road. For this reason, uphill cable pulling with forest tractor have been examined in terms of efficiency in this study. The study was carried out at Çınarpinar Forest Enterprise Chief of Kahramanmaraş Forest Enterprise Directorate. MB Trac 900, forest tractor performed for 10-350 meter cable skidding distances were measured by using a stopwatch during the operation by uphill cable pulling method, and then productivity calculation was done. At the end of the study, the average productivity was found to be $15.84 \mathrm{~m} 3 /$ hour, the mean skidding distance was $18,39 \mathrm{~m}$, and the average timber volume was $0.40 \mathrm{~m} 3$.

Key words: Extraction, MB Trac 900, Productivity, Time Study 


\title{
ORMAN TRAKTÖRÜYLE YAMAÇ YUKARI SÜRÜTME ÇALIŞMALARININ DEĞERLENDİRILLMESİ
}

\begin{abstract}
Ülkemizde ormancılıkta bölmeden çıarma çalışmaları insan gücüyle, hayvan gücüyle ve traktörlerle gerçekleştirilmektedir. Yol altında kalan tomrukların insan gücü ve hayvan gücüyle yamaç yukarı taşınması imkansı hale geldiğinden traktör kullanımı kaçınılmaz bir hal almaktadır. Bu nedenle bu çalı̧̧mada orman traktörüyle yamaç yukarı kablo çekimi çalışmaları verim açısından incelenmiştir. Çalışma Kahramanmaraş Orman Bölge Müdürlüğü, Kahramanmaraş Orman Işsletme Müdürlüğ̈̈, Çınarpınar Orman İşletme Şefliği sınırlarında yer alan kızılçam meşceresinde gerçekleştirilmişstir. MB Trac 900 marka orman traktörü ile 10-35 metrelik sürütme mesafesinden yamaç yukarı kablo çekimi yöntemiyle sürütme çalışmaları sırasında kronometre yardımıyla zaman ölçümleri yapılmış ve ardından verim hesabı yapılmıştır. Çalışmanın sonunda ortalama verim $15,84 \mathrm{~m} 3 /$ saat, ortalama sürütme mesafesi $18,39 \mathrm{~m}$ ve ortalama toplam hacim 0,40 m3 olarak tespit edilmiştir.
\end{abstract}

Anahtar Kelimeler: Bölmeden Çıkarma, MB Trac 900, Verim, Zaman Ölçümü

\section{Giriş}

.Ormancılıkta üretim çalışmaları kesme ve devirme, boylama, kabuk soyma, bölmeden çıkarma, yükleme, taşıma, boşaltma ve istifleme aşamalarından oluşmaktadır[1]. Üretim çalışmalarının en zorlu aşamaları arasında yer alan bölmeden çıkarma çalışmaları en fazla zaman alan işler arasında yer almaktadır. Ülkemizde bölmeden çıkarma çalışmaları insan gücüyle (kaydırarak, taşıyarak, basit el gereçleri kullanarak), hayvan gücüyle, traktörlerle (tarım traktörleri ve orman traktörleri) ve hava hatlarıyla gerçekleştirilmektedir[2].

Ülkemizde orman içerisinde ve çevresinde yaşayan orman köylüsüne geçim kaynağı sağlamak amacıyla çoğunlukla insan gücüyle bölmeden çıkarma çalışmaları gerçekleştirilmektedir. Ancak insan gücüyle bölmeden çıkarma, doğrudan zemin üzerinde kaydırma ya da istif odunlarının ve yakacak odunların ya da ince çaplı ürünlerin taşınması şeklinde gerçekleşmektedir[3]. İnsan gücüyle eğimli bir arazide ağır tomrukların yamaç yukarı sürütülmesi mümkün olamamaktadır. Aynı zamanda dağlık arazide hayvan gücüyle de yamaç yukarı çekim yapılamamaktadır. Bu nedenle özellikle yol altında ve dere içindeki tomrukların yamaç yukarı sürütülerek bölmeden çıkarılmasında traktörler kullanılmaktadır[4].

Ülkemizde ormancılık alanında ilk mekanizasyon kullanımına tarım traktörlerinin dizayn edilmesi ile başlanmıştır. Daha sonra tarım traktörlerinin, çeşitli ekipmanlarla modifiye edildikten ve 
güçlendirildikten sonra bölmeden çıarma çalışmalarında; sürütücü, kablo çekimi, yükleyici, taşıyıcı ve vinçli hava hattı olarak kullanılmıştır[5]. Hızlı gelişen teknoloji ile birlikte orman traktörleri tarım traktörlerine göre orman ürünlerinin bölmeden çıkarılmasında yeni imkanlar sunmuştur[6]. Orman traktörleri çok küçük yarıçaplı kurplarda dönüş ve manevra kabiliyetine sahip olmakla birlikte \%50 eğime kadar kısa, orta ve uzun boylu orman ürünlerini sürütme kabiliyetine sahiptir[7]. Aynı zamanda, orman traktörleri sürütme sırasında tomrukların bir ucunu kaldırarak da bölmeden çıkarma çalışmalarını gerçekleştirebilmektedir[8]. Bu nedenle bu çalışmada orman traktörüyle yamaç yukarı sürütme çalışmalarının verimliliği değerlendirilmiştir.

\section{Yöntem}

\section{1. Çalışma Alanı}

Arazi çalışmaları Kahramanmaraş Orman Bölge Müdürlüğü, Kahramanmaraş Orman İşletme Müdürlüğü, Çınarpınar Orman İşletme Şefliği 123 no'lu bölme içerisinde gerçekleştirilmiştir (Şekil 1).

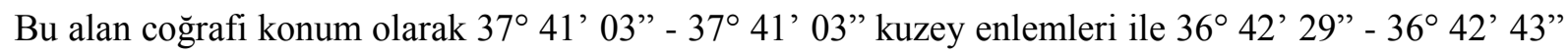
doğu boylamları arasındadır. Araştırma alanı sınırları 32,2 ha ormanlık alanı kaplamaktadır. Araştırma alanının denizden yüksekliği 776 m ve ortalama eğimi \% 14,2'dir. Bölmeden çıkarmanın yapıldığı alan kızılçam (Çzcd1 ve Çzcd2) meşcerelerinden oluşmaktadır.

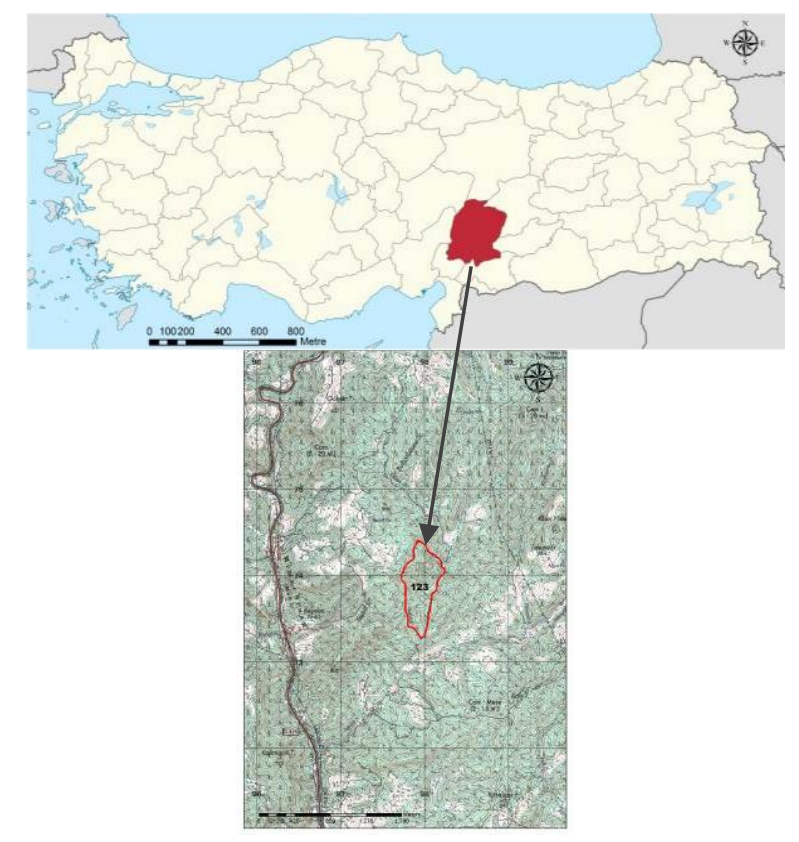

Şekil 1. Çalışma Alanı 
Bölmeden çıkarma çalışmalarında MB Trac 900 orman traktörü kullanılmıştır (Şekil 2). Sürütülecek odun hammaddelerinin çapları çap ölçer, boyları boy ölçer ve ortalama arazi eğimi ise eğimölçer yardımıyla belirlenmiştir. Zaman ölçümü için iki adet kronometre kullanılmıştır.

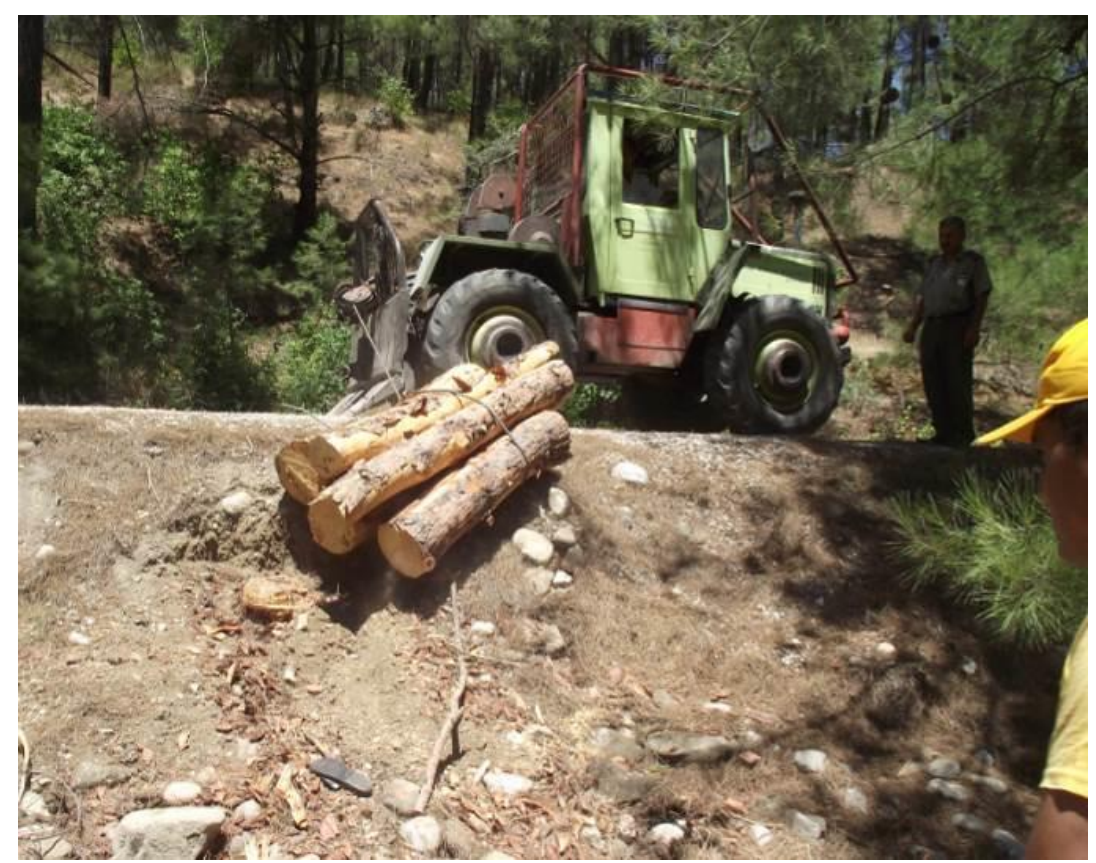

Şekil 2. MB Trac 900 Orman Traktörü

\subsection{Metod}

Orman traktörüyle kablo çekimi yapmak suretiyle bölmeden çıkarma çalışmaları toplam dört kişilik işçi ekibi tarafından gerçekleştirilmiştir. Yamaç altında yolun bulunmadığı alanlarda tomrukların yol kenarına çekilmesi amacıyla bir adet orman traktörü kullanılmıştır. İki adet kronometre yardımıyla 50 sefer için tekrarlı zaman ölçümü yöntemi gerçekleştirilmiştir. Çalışmada sürütme kancasının tomruklara çekilmesi, sürütme kancasının tomruklara bağlanması, tomrukların sürütülmesi, sürütme kancasının çıkarılması ve hazırlık aşaması değerlendirilmiştir.

Orman traktörüyle bölmeden çıkarma çalışmaları bir işçinin sürütme kancasını tomrukların yanına çekmesiyle başlamıştır. Geçen süre sürütme kancasının tomrukların yanına çekilme zamanı olarak zaman etüt formuna kaydedilmiştir. Hemen ardından diğer bir kronometre çalıştırılmış ve sürütme kancasının tomruklara bağlanma zamanı ölçülerek kaydedilmiştir. Sürütme kancasının bağlanmasıyla birlikte operatör işçi tarafından traktör vinci çalıştırılarak tomrukların traktör vincine doğru yamaç yukarı çekilmesi sağlanmıştır. Yamaç yukarı çekme aşamasında geçen süre sürütme zamanı olarak ölçülmüsstür. Sürütülen tomruklar traktörün yanına geldiği anda kronometre durdurularak okunan değer etüt formuna kaydedilmiştir. Bu sırada yardımcı tarafından diğer bir kronometreyle sürütme kancasının çıkarılma zamanı ölçülmüş ve okunan değer kaydedilerek bölmeden çıkarma aşaması tamamlanmıştır. 
Tomrukların hacmi teknik ormancılık uygulamalarında yaygın olarak kullanılan "Orta Yüzey Formülü (Huber Formülü)" ile hesaplanmıştır[8]. Ardından, zaman ölçümü ile elde edilen veriler kullanılarak üretim çalışmalarının saatlik verimi (m3/saat) değerlendirilmiştir.

\section{Sonuçlar}

$\mathrm{Bu}$ çalışma Kahramanmaraş Orman Bölge Müdürlüğü, Çınarpınar Orman İşletme Şefliği sınırlarında yer alan kızılçam meşceresinde gerçekleştirilmiştir. MB Trac 900 marka orman traktörü ile 10-35 metrelik sürütme mesafesinden yamaç yukarı kablo çekimi uygulanmıştır. Bölmeden çıkarma çalışmaları sırasında kronometreyle 50 adet zaman ölçümü gerçekleştirilmiştir. Elde edilen zaman değerleriyle çalışmanın verim hesabı yapılmıştır. Sonuç olarak orman traktörüyle yamaç yukarı sürütme çalışmalarında ortalama sürütme mesafesi $30 \mathrm{~m}$, ortalama hacim $0,44 \mathrm{~m} 3$ ve ortalama verim 15,84 m3/saat, olarak tespit edilmiştir. Elde edilen sonuçlar ve önceki çalışmalardan elde edilen sonuçlara göre sürütme mesafesi arttıkça verim azalmıştır. Bu nedenle orman traktörüyle kısa mesafelerde çalışmanın daha verimli olacağı görülmüştür.

Ülkemizde son yıllarda orman köylerinde yaşayan genç nüfusun azalması ve ormancılık işlerinde çoğunlukla yaşlı nüfusun çalışması nedeniyle mekanik araçlara bir yönelme olmuştur. Bu nedenle bölmeden çıkarma çalışmalarından özellikle yamaç yukarı sürütme işlerinde orman traktörü kullanımı güçlü bir çözüm olacağı düşünülmektedir. Bu konuda orman köy kooperatifleri ve orman işletmelerinin yamaç yukarı bölmeden çıkarma çalışmalarında ve dere altında kalan tomrukların çekilmesin verimli bir şekilde kullanabileceği önerilmektedir. 


\section{Kaynakça}

[1] Acar, H.H., 1995. Dağlık Arazide Kısa Mesafeli Mobil Orman Hava Hatları ile Bölmeden Çıkarma Çalışmalarının İncelenmesi. Tr. J. of Agriculture and Forestry (21): 195-200.

[2] Akay, 2005. Using Farm Tractors in Small-Scale Forest Harvesting Operations. Journal of Applied Sciences 1(2): 196-199.

[3] Erdaş, O., Acar, H.H., Eker, M., 2014. Orman Ürünleri Transport Teknikleri. Karadeniz Teknik Üniversitesi, Orman Fakültesi, KTÜ Matbaası, Trabzon, Genel Yayın No: 233, Fakülte Yayın No: $39,504 \mathrm{~S}$

[4] Gülci, N., 2014. Üretim Planlamasında Hassas Ormancılık Üzerine Araştırmalar. Doktora Tezi, Kahramanmaraş Sütçü İmam Üniversitesi, Orman Fakültesi, Kahramanmaraş. 264 s.

[5] Öztürk, T., 2009. Kayın Tomruğunun Bölmeden Çıkarılmasında MB Trac 900 Sürütücünün Verimlilik Analizi. İstanbul Üniversitesi Orman Fakültesi Dergisi, Series A, 59(2 ): 45-58

[6] Öztürk, T., Şentürk, N., 2010. Productivity and Time Studies of MB Trac 900 Tractor at Beech Standson Mountainous Areas in Turkey. Baltic Forestry, 16 (1): 132-137.

[7] Spinelli R, Magagnotti, N., (2012). Wood extraction with farm tractor and sulky: estimating productivity, cost and energy consumption. Small-scale For 11(1):73-85.

[8] Yıldırım, M., Engür, O. 1989. Ormanda Bölmeden Çıkarma. İstanbul Üniversitesi Orman Fakültesi Dergisi, 39(4):84-99. 